\title{
Anterior Transcervical Lag Screw Fixation of Type II Odontoid Fracture
}

\author{
Dinuj Shrestha $M B B S^{1}$, Pratyush Shrestha $M C h^{2}$ \\ 1,2Upendra Devkota Memorial National Institute of Neurological and Allied Sciences, Kathmandu, Nepal \\ Date of submission: $23^{\text {rd }}$ May 2020 \\ Date of acceptance: $14^{\text {th }}$ July 2020 \\ Date of publication: $12^{\text {th }}$ August 2020
}

\begin{abstract}
Odontoid fracture comprises approximately $20 \%$ of all cervical spine fractures. Among them type II fracture accounts for about $65-74 \%$. Presently, direct anterior screw fixation is considered to provide successful outcome with fracture healing of $80 \%$ and also preserve $\mathrm{C} 1 / \mathrm{C} 2$ rotation movement with benefit of early mobilization and rapid return to normal life style. Recent fracture ( $<6$ months) have a high fusion rate of $90 \%$ with this approach and for remote fracture ( $\geq 18$ months) it reduces to $25 \%$. Here we present a case report of an 18 years old female with type II odontoid fracture and underwent anterior transcervical lag screw fixation under C-arm guidance.
\end{abstract}

Key words: C-arm guidance, Cervical Spine, Odontoid fracture, Transcervical lag screw fixation

\section{Introduction}

Osis dontoid fracture accounts for approximately $20 \%$ of all the cervical spine fractures. ${ }^{1}$ They are also the most common spinal fractures in patient older than 80 years. $^{2}$ They are classified into 3 categories according to Anderson \& D'Alonso depending upon location and extent of fracture line. ${ }^{3}$ The most common is type II fracture which accounts for $65-74 \%$ and is also known to be relatively unstable. ${ }^{3,4}$

The most appropriate treatment for type II odontoid fracture is controversial., ${ }^{4,5}$ Some believe posterior C1-

\footnotetext{
Access this article online

Website: https://www.nepjol.info/index.php/NJN

DOI: https://doi.org/10.3126/njn.v17i2.30180

HOW TO CITE

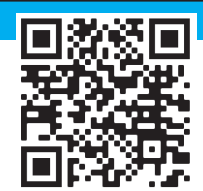

Shrestha D, Shrestha P. Anterior Transcervical Lag Screw Fixation of Type II Odontoid Fracture. NJNS. 2020;17(2):75-76

${ }^{1}$ ORCID id: 0000-0002-7395-8194

${ }^{2}$ ORCID id: 0000-0003-0469-2131

\section{Address for correspondence:}

Dr. Pratyush Shrestha

Upendra Devkota Memorial National Institute of Neurological and Allied Sciences

Bansbari, Kathmandu, Nepal

Contact number: +977-9841556852

E-mail: pratyush@neuro.org.np

Copyright (C) 2020 Nepalese Society of Neurosurgeons (NESON)

ISSN: 1813-1948 (Print), 1813-1956 (Online)
}

C2 fusion has best clinical results especially in elderly patients. ${ }^{6,7}$ Direct anterior screw fixation; however, is an effective and safe method for treating recent odontoid fractures ( $<6$ months), while lower rate of fusion is found in remote fractures ( $\geq 18$ months)..$^{8,9,10}$ This approach is suitable only in cases with intact transverse ligament ${ }^{11}$ and a fracture line extending from anterior-superior to posterior-inferior. ${ }^{5,12}$ Here we present a case report of an 18-year-old female with type II odontoid fracture who underwent anterior transcervical lag screw fixation under $\mathrm{C}$-arm guidance, as not much has been reported on this entity from our country Nepal. ${ }^{13}$

\section{Case Report}

An 18-year-old female presented to our casualty with alleged history of fall from a one-storied building of about 10 feet height. She had loss of consciousness for about a minute and severe pain over the nape of the neck. Clinically, she had stable vitals and a Glasgow coma scale (GCS) of 15/15. Motor examination revealed power of $5 / 5$ in all major muscle groups of upper and lower limbs with intact sensation on all dermatomes. Screening X-ray cervical spine and subsequent computed tomography (CT) scan of the cervical spine revealed a type II odontoid fracture (Figure 1). Magnetic Resonance Imaging (MRI) of the cervical spine did not show any cervical cord injury and the transverse ligament was intact (Figure 2). CT scan of the brain was also normal.

The Philadelphia cervical collar applied in the casualty was hence continued and she was admitted for surgical stabilization.

Awake fiber-optic nasotracheal intubation was done and the patient placed supine with the neck extended. 


\section{Shrestha et al}

A small, transverse skin incision made at the level of cricothyroid (C5-6 level). Prevertebral fascia was reached, dissecting in the avascular plane, retracting the trachea and oesophagus medially and sternocleidomastoid muscle and carotid sheath laterally. Dissection carried cranially and C2-3 interspace identified fluoroscopically. A midline gutter was cut on the anterior body of C3 vertebra and C2-3 disc and the antero-inferior endplate of $\mathrm{C} 2$ vertebra visualized. A $2 \mathrm{~mm}$ Kirschner $(\mathrm{K})$ wire drill was drilled cranially through the $\mathrm{C} 2$ vertebral body fracture line, up to the cortex of the odontoid tip, under real-time fluoroscopic guidance. The drill hole was tapped over the K-wire and the length of the screw required measured. A non-selftapping, lag screw was then cannulated just upto the apical cortex of the odontoid tip. The wound was closed in two layers on a suction drain.

Postoperatively her neurology was intact and there were no complications. Postoperative x-ray of cervical spine revealed proper position of lag screw (Figure 3 ). Philadelphia collar was applied for 14 days. Flexion and extension X-ray cervical spine done after 3 months showed adequate fusion of the fractured segment. Rotatory movement at the neck was preserved and the patient did not have any problem during this follow up.

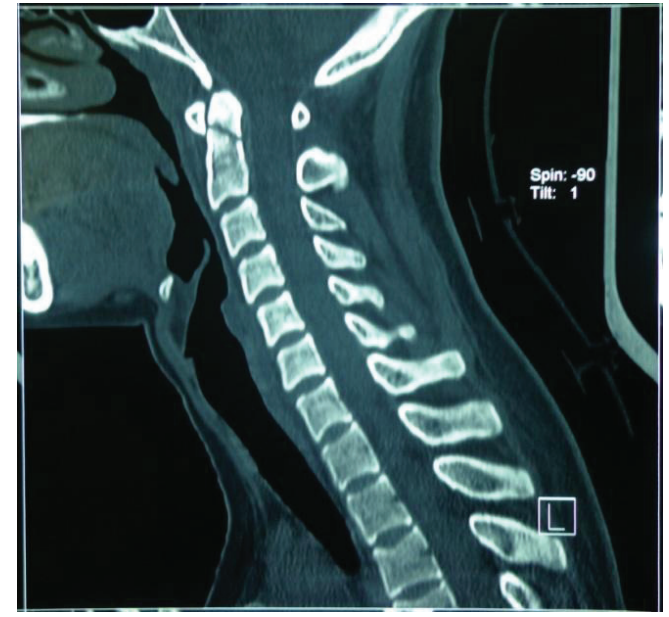

Figure 1: Sagittal section CT scan of cervical spine showing type II odontoid fracture without displacement.

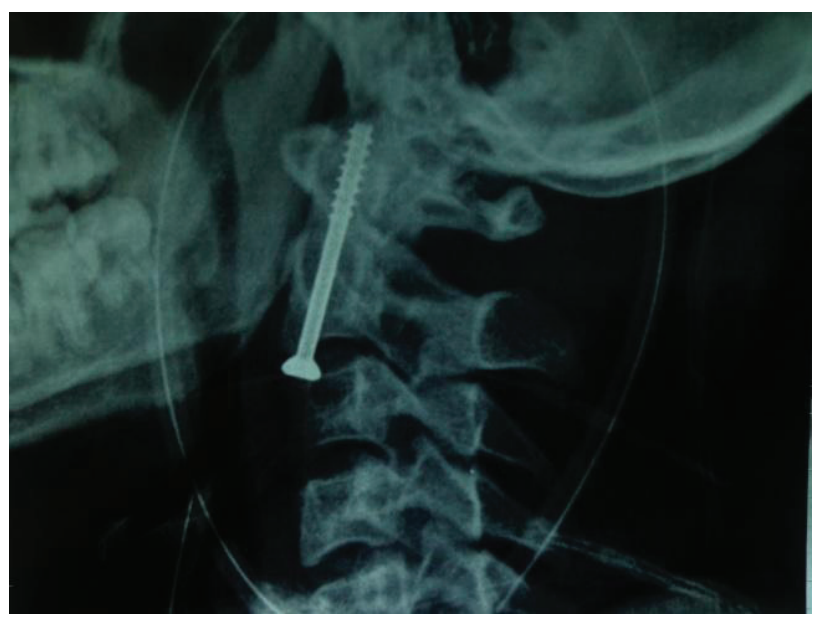

Figure 3: Postoperative lateral radiograph showing proper reduction and fixation of type II odontoid fracture with single lag screw.
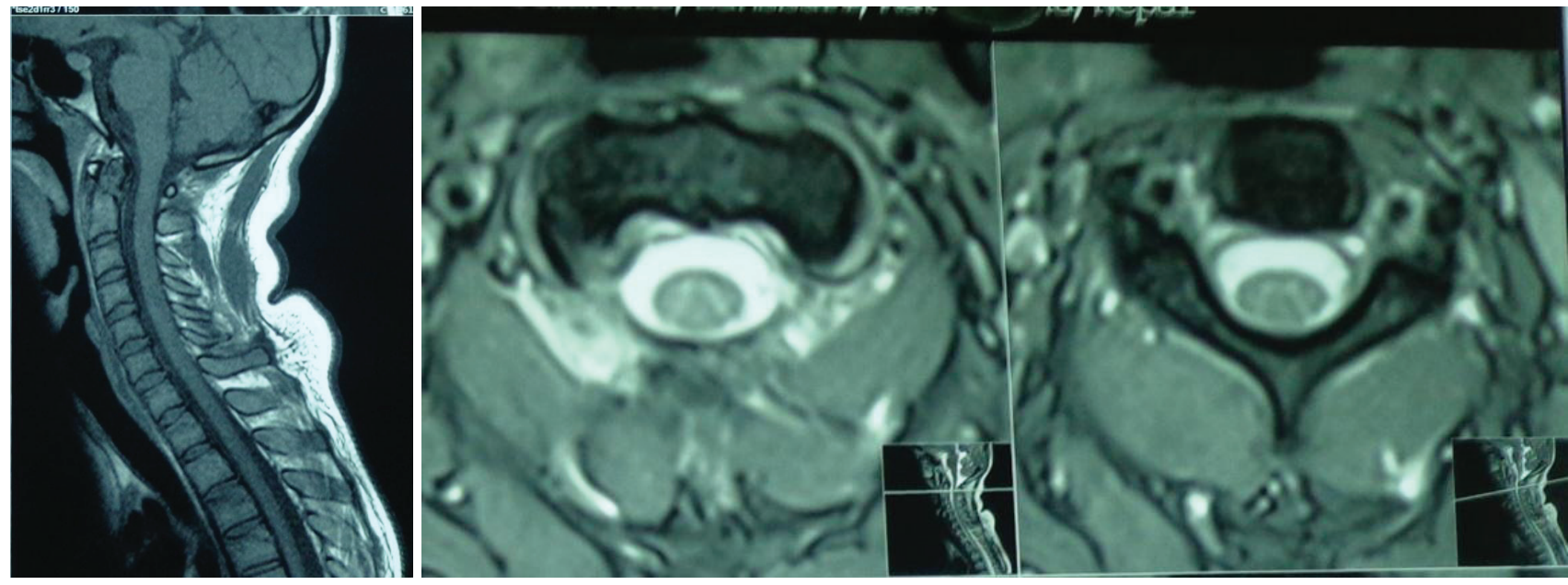

Figure 2: T1 and T2 weighted MRI of the cervical spine shows intact cervical cord and the transverse ligament (arrow). 


\section{Anterior Transcervical Lag Screw Fixation of Type II Odontoid Fracture}

\section{Discussion}

When this patient was operated on, real time biplaner imaging was not available even in a tertiary centre as ours, and the radiographer had his share of activity in guiding the surgeons in planning the trajectory of the screw. Appropriate treatment for type II dens fracture remains controversial., ${ }^{4,5}$ Posterior $\mathrm{C} 1-\mathrm{C} 2$ fusion gives best clinical results especially in elderly patients 6,7 however, it compromises the $\mathrm{C} 1-\mathrm{C} 2$ rotational movement of the neck which is $50 \%$ of the total cervical rotatory movement. ${ }^{8}$ Direct anterior screw fixation has been shown to result in successful fracture healing in $80 \%$ cases ${ }^{6,14}$ moreover it preserves $\mathrm{C} 1-\mathrm{C} 2$ rotatory movement and also allows early mobilisation as well as rapid return to normal lifestyle ${ }^{10,15}$ as can be instanced in our case. There can be many technical problems during anterior screw fixation as inability to gain access to the dens while keeping the fracture reduced and displacement of screws, as well as non-union in osteoporotic bones of elderly patients. ${ }^{6}$ The effectiveness of the fusion is also determined by the orientation of the fracture line. The rate of anatomical bone fusion in recent fractures was found significantly higher in fractures oriented horizontally and posterior oblique direction compared to anterior oblique direction. ${ }^{8}$ Our patient had a fracture line that was directed in posterior oblique direction and hence was a suitable candidate for screw fixation. The fusion rate is about $90 \%$ when operated within 6 months but this significantly reduces to $25 \%$ for remote fracture ( $\geq 18$ months). ${ }^{8,10,15}$ Anterior screw fixation is avoided when ligament injury is present. ${ }^{8}$ Due to unstable nature of type II odontoid fracture, it is important to treat it as early as possible to prevent disastrous consequences.

\section{Conclusion}

Anterior transcervical lag screw fixation can be considered as the choice of surgical treatment in Type II Odontoid fracture though it is suitable only in cases with intact transverse ligament and a fracture line extending horizontally or postero-inferiorly. This surgical technique confers immediate stability and adequate fusion without significant major complications. Also, C1-C2 rotation movement of neck is preserved and early mobilization can be achieved.

\section{Acknowledgement}

We would like to acknowledge that Late Professor Upendra Prasad Devkota was the senior author of this case report accepted for publication in November 2017. The senior author of this article had been actively involved in the neurosurgical field in Nepal over the last three decades and this was the first surgery of this kind performed by him in Nepal. Though regularly practiced around the world, we did not find evidence in literature of such surgical endeavor in this part of the world, then.

\section{Conflict of Interest: None \\ Source(s) of support: None}

\section{References}

1. Lee PC, Chun SY, Leong JC. Experience of posterior surgery in atlanto-axial instability. Spine. 1984;9(3):231-9. https://doi.org/10.1097/00007632198404000-00002

2. Elgafy H, Dvorak MF, Vaccaro AR, Ebraheim N. Treatment of displaced type II odontoid fractures in elderly patients. Am J Orthop. 2009;38(8):410-6.

3. Anderson LD, D'Alonzo RT. Fractures of the odontoid process of the axis. J Bone Joint Surg Am. 1974;56(8):1663-74. https://doi. org/10.2106/00004623-197456080-00017

4. Denaro V, Papalia R, Di Martino A, Denaro L, Maffulli N. The best surgical treatment for type II fractures of the dens is still controversial. Clin Orthop Relat Res. 2011;469(3):742-50. https://doi. org/10.1007/s11999-010-1677-x

5. Pal D, Sell P, Grevitt M. Type II odontoid fractures in the elderly: an evidence-based narrative review of management. Eur Spine J. 2011;20(2):195-204. https://doi.org/10.1007/s00586-010-1507-6

6. Andersson S, Rodrigues M, Olerud C. Odontoid fractures: high complication rate associated with anterior screw fixation in the elderly. Eur Spine J. 2000;9(1):56-9. https://doi.org/10.1007/ s005860050009

7. Scheyerer MJ, Zimmermann SM, Simmen HP, Wanner GA, Werner CM. Treatment modality in type II odontoid fractures defines the outcome in elderly patients. BMC Surg. 2013; 13:54. https://doi. org/10.1186/1471-2482-13-54

8. Apfelbaum RI, Lonser RR, Veres R, Casey A. Direct anterior screw fixation for recent and remote odontoid fractures. J Neurosurg. 2000; 93:227-36. https://doi. org/10.1186/1471-2482-13-54

9. Rao G, Apfelbaum RI. Odontoid screw fixation for fresh and remote fractures. Neurol India. 2005;53(4):416-23. https://doi.org/10.1186/14712482-13-54

10. Srinivasan US, Dhillon CS, Mahesha K, Kumar P. Anterior single lag screw fixation in type II Dens 


\section{Shrestha et al}

fracture - indian experience. The Indian Journal of Neurotrauma. 2008;5(2):87-91. https://doi. org/10.1016/S0973-0508(08)80006-8

11. Greene KA, Dickman CA, Marciano FF, Drabier J, Drayer BP, Sonntag VK. Transverse atlantal ligament disruption associated with odontoid fractures. Spine. 1994;19(20):2307-14. https://doi. org/10.1097/00007632-199410150-00010

12. Jaiswal AK, Sharma MS, Behari S, Lyngdoh BT, Jain S, Jain VK. Current management of odontoid fractures. The Indian Journal of Neurotrauma. 2005;2(1):3-6. $\quad$ https://doi.org/10.1016/S09730508(05)80003-6
13. Cherian I. Neurosurgery in the himalayas. Asian $\mathbf{J}$ Neurosurg. 2010;5(1):101-10.

14. Harrop JS, Przybylski GJ, Vaccaro AR, Yalamanchili $\mathrm{K}$. Efficacy of anterior odontoid screw fixation in elderly patients with Type II odontoid fractures. Neurosurg Focus. 2000;8(6): e6. https://doi. org/10.3171/foc.2000.8.6.7

15. Dickman CA, Foley KT, Sonntag VK, Smith MM. Cannulated screws for odontoid screw fixation and atlantoaxial transarticular screw fixation. Technical note. J Neurosurg. 1995;83(6):1095-2000. https:// doi.org/10.3171/jns.1995.83.6.1095 